\title{
Efficacy of auriculotherapy for the reduction of stress in nursing students: a randomized clinical trial
}

\author{
Juliana Miyuki do Prado ${ }^{1}$ \\ Leonice Fumiko Sato Kurebayashi \\ Maria Júlia Paes da Silva ${ }^{3}$
}

This study is a randomized single-blind trial, which aimed to evaluate the efficacy of true auriculotherapy and placebo auriculotherapy in reducing the stress levels of mid-level Nursing students of the School of Nursing of the Beneficência Portuguesa Hospital. Seventyone students with average, high and very high scores, according to Vasconcellos' List of Stress Symptoms, were divided into three groups: Control (25), Auriculotherapy (24), and Placebo/Sham (22). They were evaluated at the baseline, 8th and 12th sessions and at the follow-up (15 days) and received Shen Men and Brainstem points (Auriculotherapy Group) and Wrist and Outer Ear points (Placebo/Sham Group). The analysis of variance (ANOVA) showed statistically significant differences between the Control/Auriculotherapy groups from the 8th session, which was maintained in the third and fourth evaluations $(p=0.000)$ and between the Control/Placebo groups $(p<0.05)$ at the three evaluations. It was concluded that the true auriculotherapy obtained better responses (45.39\%) than the placebo $(34.18 \%)$ in the reduction of the stress, but further studies are recommended for the re-evaluation of the sham points for stress. ClinicalTrials.gov Identifier: NCT01420848.

Descriptors: Students, Nursing; Auriculotherapy; Stress.

\footnotetext{
${ }^{1}$ RN, Specialist in Clinical Nutrition, Real e Benemérita Associação Portuguesa de Beneficência, Brazil.

2 Doctoral student, Escola de Enfermagem, Universidade de São Paulo, Brazil.

${ }^{3}$ PhD, Full Professor, Escola de Enfermagem, Universidade de São Paulo, Brazil.
} 


\title{
Eficácia da auriculoterapia para diminuição de estresse em estudantes de enfermagem: ensaio clínico randomizado
}

Trata-se de estudo clínico randomizado, simples cego, com o objetivo de avaliar a eficácia da auriculoterapia verdadeira e placebo na diminuição dos níveis de estresse em alunos de nível médio, da Escola de Enfermagem do Hospital Beneficência Portuguesa. Setenta e um estudantes com escores médio, alto e altíssimo, pela Lista de Sintomas de Estresse de Vasconcellos, foram divididos em 3 grupos: controle (25), auriculoterapia (24) e placebo/Sham (22). Foram avaliados, no início, com 8, 12 sessões e follow-up (15 dias) e receberam os pontos Shen Men, tronco cerebral (auriculoterapia) e punho e ouvido externo (placebo/Sham). Na análise de variância (Anova) constataram-se diferenças estatísticas significativas entre os grupos controle/auriculoterapia a partir de 8 sessões, mantendo-se após a terceira e a quarta avaliação $(p=0,000)$ e entre controle/placebo $(p<0,05)$, nas três avaliações. Concluiu-se que a auriculoterapia verdadeira obteve melhores respostas $(45,39 \%)$ do que o placebo $(34,18 \%)$ na redução do estresse, mas recomendam-se mais estudos para reavaliação de pontos Sham para estresse. ClinicalTrials.gov Identifier: NCT01420848.

Descritores: Estudantes de Enfermagem; Auriculoterapia; Estresse.

\section{Eficacia de la auriculoterapia para la disminución del estrés en estudiantes de enfermería: ensayo clínico aleatorio}

\begin{abstract}
Este ensayo clínico aleatorio simple-ciego tuvo el objetivo de evaluar la eficacia de la auriculoterapia verdadera y auriculoterapia placebo en la disminución del estrés de los estudiantes de la Escuela de Enfermería del Hospital Beneficência Portuguesa. Setenta y un alumnos com puntuaciones medias, altas y altísimas por la Lista de Síntomas de Estrés de Vasconcellos se dividieron en 3 grupos: Control (25), Auriculoterapia (24), Placebo/Sham (22). Se evaluaron al inicio, con 8, 12 sesiones y seguimiento (15 días). En la ANOVA se encontraron diferencias estadísticamente significativas entre os grupos de Control/Auriculoterapia en las 3 evaluaciones $(P=0,000)$ y entre Control/Placebo $(P<0,05)$. Se concluyó que la auriculoterapia obtuvo mejor respuesta $(45,39 \%)$ que el placebo $(34,18 \%)$ en reducir el estrés. Se recomiendan más estudios para la reevaluación de los puntos sham de estrés. ClinicalTrials.gov Identifier: NCT01420848.
\end{abstract}

Descriptores: Estudiantes de Enfermería; Auriculoterapia; Estrés.

\section{Introduction}

Stress is a process that can be experienced either positively or negatively by an individual. How each person responds to the different stress factors is a particular and circumstantial phenomenon, mediated by the social and cultural context. However, it is known that if stress levels persist intensely, initial adaptability can give way to physiological, emotional, endocrine, immunological and neurological pathological alterations, making the individual vulnerable to illness. Selye first used the term stress in the area of health in 1936 to define a set of physiological reactions that the body develops when faced with a situation of stress, triggered by homeostasis threatening stimulation, generating diverse symptoms ${ }^{(1)}$. This set of physical, chemical, biological or psychosocial non-specific reactions are know as the "General Adaptation Syndrome" which consists of three successive phases: Alarm Phase, Adaptation or Resistance and Exhaustion Phase (2).

The Alarm phase occurs when a person perceives the stressor agent and prepares to fight or flee, 
undergoing hormonal alterations. Under stimulation of the Sympathetic Nervous System, adrenaline and noradrenalin are secreted by the adrenal gland. This phase ends within hours, when the stressor is of short duration. If the stressor is prolonged and persists, the individual will enter the Resistance phase, which is a period of adaptation to the stress. The person tries to resist making use of adaptive energy reserves in search of a rebalance after the breakdown of the homeostasis. Alterations occur in the adrenal glands and the medulla decreasing the production of adrenaline, however, the cortex of the adrenal glands produces more corticoids. If the stressor continues even longer, the person enters the Exhaustion phase, making the body vulnerable to disease and dysfunction ${ }^{(3)}$.

Although the studies on stress have a strong focus on work stress, to evaluate stress among nursing students allows the observation of the stress factors that are experienced in a negative and nonadaptive way and interfere with success in the school activities. Feelings of withdrawal can translate into apathy and lack of motivation to carry out academic activities. The students can experience symptoms of the Alarm phase of stress, such as: tachycardia, muscle tension, cold extremities and skin; and also of the second phase of stress, such as: headache, drowsiness, irritability and difficulty concentrating. High levels of stress present a substantial effect on the attention span and may lead to errors, lack of concentration and fluctuations in the level of attention. In addition, stress influences the acquisition, manipulation and consolidation of the received information. Thus, it can be said that this behavioral alteration can negatively affect the learning and performance of the student ${ }^{(4)}$.

There are multiple factors that can lead students to the feeling of self-depreciation and low self-esteem, which can be a generator of stress in teaching-learning situations in nursing. The exposure situations in internships, in which the students are taken from the theoretical and hypothetical situations into a practical and real approach, are the high points of stress. Students experience the practical care as a verdict on their professional skills and experience great fear of committing mistakes, of being exposed in front of the clients, the teachers and also the other students. Various other difficulties can be listed, such as: contact with the physical and emotional intimacy of the clients, clients that are difficult to care for or undergoing palliative care, the fear of contracting infections and of making mistakes, and the ethical dilemmas with which they must deal daily. Added to this is the difficulty of combining work and study, leisure and family and expectations related to the professional future(5-6).

The eastern cultures have historically developed Coping Strategies from bodily practices, exercises, movements, dances and massage, aiming to preserve and restore health through the flexibility and strengthening of the body and mind(7). The benefits of such practices, including auriculotherapy, for maintaining the quality of life by reducing the day-to-day tensions, has been reported in studies over the last 10 years in different countries $^{(8-11)}$.

Chinese auriculotherapy is one of a set of practices performed in traditional Chinese medicine and has been commonly used for millennia, not as a single technique, but as an adjunct and complement to other practices, such as systemic acupuncture, phytotherapy, massage, physical exercises, diet, moxibustion, cupping etc. There are currently two main lines of research in auriculotherapy worldwide, the French Auriculotherapy of Nogier(12) and the Chinese. Although other auriculotherapy maps are being developed, there is some consensus between these two maps and their applicability in different types of conditions of imbalance and disease. The French school determines the auricular microsystem as reflexology of a neurological action, i.e. conducted by the parasympathetic system. When perforating a particular area of the auricular cartilage, an area of the brain is stimulated, from that point, discharging endorphins that act on the bodily system, triggering the release of a neurotransmitter. The Chinese line of auriculotherapy bases the choice of points on the principles of Traditional Chinese Medicine $(\mathrm{TCM})^{(13)}$.

Due to the different references regarding the location and function of such auricular points, this study questioned whether the points chosen for the auriculotherapy group would be more efficacious than sham points, which, according to the literature, would not be indicative for the intended purposes.

Regarding the ethical-legal aspects concerning the performance of acupuncture by the nurse, it is noteworthy that legal support was obtained, through Resolution 197/97 of the Federal Council of Nursing (COFEN), for the practice of acupuncture and auriculotherapy. Currently, Resolution 326/2008 exists, replacing the previous resolutions providing for the registration of the specialty, giving support and legitimacy to the practice of acupuncture by the nurse ${ }^{(14)}$. 


\section{Aim}

The aim of this study was to evaluate the efficacy of true auriculotherapy and placebo auriculotherapy in reducing the stress levels of mid-level nursing students of the São Joaquim School of Nursing of the Beneficência Portuguesa Hospital.

\section{Method}

\section{Type of study}

This is a randomized controlled clinical trial with three groups: Auriculotherapy group (intervention), Control group (no intervention) and Placebo group (with sham points).

\section{Ethical and Legal Aspects}

The research project was accepted by the Research Ethics Committee of the Beneficência Portuguesa Hospital of São Paulo with protocol number 672-11 and by the National Health Council (CONEP) under CAAE number 0107.0.360.000-11. The study also considered Resolution 196/1996 of the National Health Council, regarding the involvement of human beings in the study. The Terms of Free Prior Informed Consent were delivered to the study subjects and the participants were assured that if they were placed in the control group they would be offered the opportunity, after the study, to be treated for the same period of time and for free.

\section{Sample}

To define the sample of the participating subjects Vasconcellos' List of Stress Symptoms - LSS ${ }^{(15)}$ was used. The instrument was applied to all those who expressed interest in participating in the study (91), however, only individuals who achieved medium, high or very high scores were invited to participate; 71 mid-level nursing students were selected for the study. The allocation of the participants was performed using opaque envelopes, sealed and numbered and then drawn by a computer program with numbers generated on the site www. randomizer.org for the three groups. Of the 71 students who were selected, 25 subjects were in the Control Group, 24 in the Auriculotherapy Group and 22 in the Placebo Group. With the sample calculation carried out, and considering previous studies on stress, the sample was affirmed to have a power of $80 \%$ for a significance level of $5 \%$, or a confidence level of $95 \%$. The inclusion criteria were: voluntary participation in the study with available time to commit to the sessions; obtaining the minimum scores of the LSS for medium, high and very high levels; not being pregnant. The exclusion criteria were: sick leave or vacation during the study; missed sessions; discontinuance of the course; collateral effects; and initiation of other energetic therapies during the study period. The appropriate exclusions were made and a sample of 71 nursing students was obtained conforming to the following diagram (Figure 1).

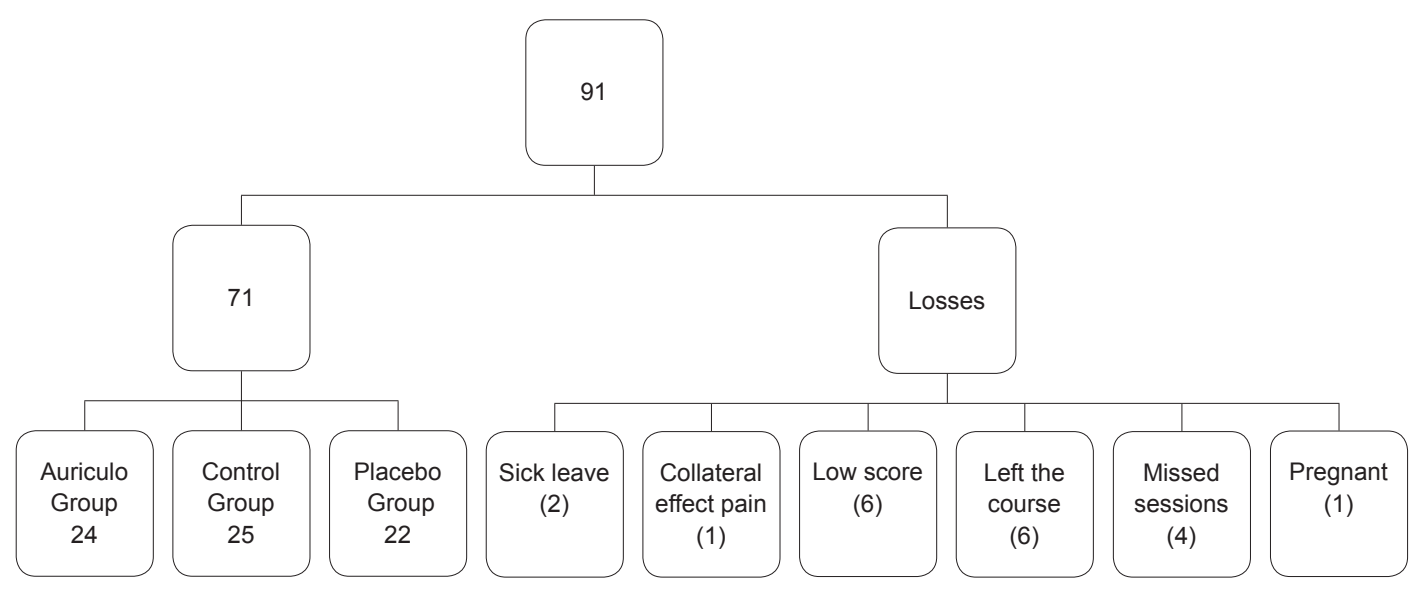

Figure 1 - Diagram of fluctuation of the study subjects. São Paulo, SP, Brazil, 2011

\section{Data collection}

The data collection instruments used were: socio-demographic data questionnaire. Data collection Vasconcellos' List of Stress Symptoms (LSS) and a was conducted between January and July 2011, at the 
nursing school and all the sessions were conducted by an acupuncturist nurse, with over five years experience in auriculotherapy (the first author of this work). In the LSS, which consists of 60 items, the frequency of the occurrence of symptoms should be recorded, from a scale of (0) never, (1) rarely, (2) often and (3) always. The total score of this inventory can vary from 0 to 177 points, with the lower scores indicating an absence of stress (0-11 points), low levels (12-28), medium levels (29-60), high levels (61 to 120) and very high levels (above 120 points).

Collection procedures: The LSS instrument was applied at the beginning, before the treatment, after eight sessions, after 12 sessions and 15 days after the termination of treatment (follow up). The Auriculotherapy group received 12 sessions (one per week), lasting 5 to 10 minutes for each session, in the Shen Men and Brainstem points. The Shen Men and Brainstem points have calming properties ${ }^{(16)}$. The sham points group also received the same number of sessions in the Wrist and Outer Ear points. Neither should be responsive to the stimulation of pressure and pain, therefore, they were previously tested with a probe before their placement. For the placement of the semipermanent needles, after the appropriate location of the reactive points with a point locator, the cleaning of the auricular pavilion, using cotton wool and $70 \%$ ethyl alcohol, and application of the needles, affixed with micropore tape, were performed.

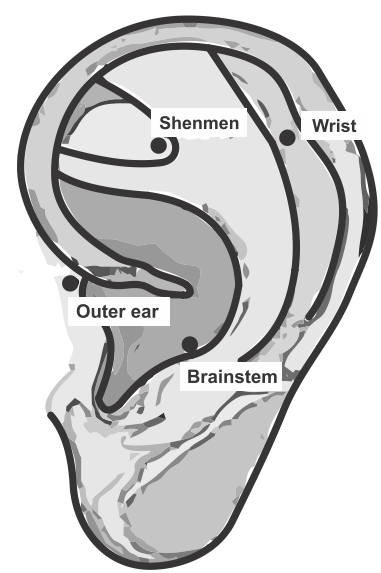

Figure 2 - Auricular points and sham points. São Paulo, SP, Brazil, 2011

Data analysis and hypotheses testing: For the inferential analysis a statistical test was performed, where the hypothesis to be tested was that there was no significant difference between the differences of the means obtained between the three groups (difference
2-1, 3-1, 4-1) at three different times (at the baseline, after 8 sessions, after 12 sessions and at the follow-up). As this hypothesis was rejected, it was concluded that there was at least one statistically significant difference and the Post Hoc was carried out to find which groups these differences would be between.

For the data analysis, the two prerequisites for the statistical analysis were satisfied: the adherence to the normal curve of the means of the three groups, from the Kolmogorov-Smirnov test and the Levene's test of homogeneity of variance. As a normal distribution was obtained for all data, parametric tests were used in the statistical analysis, the analysis of variance (ANOVA) for repeated measures. These tests were performed using the SPSS 17.0 statistical program.

\section{Results}

Of the participating subjects, $32.39 \%$ (23) obtained a medium score of stress, $64.79 \%$ (46) corresponded to the high score and $2.8 \%$ (2) presented a very high score. Regarding gender, 9.85\% (7) were male, $90.14 \%$ (64) were female and $92.95 \%$ (66) complained of stress. For the statistical analysis, the means and standard deviations of the age and stress levels were calculated (Table 1). The statistical analysis showed that the data was distributed in a normal way in the 3 groups with regard to these aspects ( $p>0.05)$.

Table 1 - Distribution of means and standard deviations, according to age and levels of stress (LSS) in the three groups. São Paulo, SP, Brazil, 2011

\begin{tabular}{lcccc}
\hline & Control & Auriculo & Placebo & p \\
\hline Age (years) & $28.68(6.57)$ & $27.21(5.97)$ & $30.91(8.34)$ & 0.307 \\
LSS (points) & $67.72(22.38)$ & $75.62(26.50)$ & $72.45(25.65)$ & 0.536 \\
\hline
\end{tabular}

Regarding the result of the ANOVA test for repeated measures, a statistical difference was found between the differences of the means of the groups at the three times, when compared between LSS2/LSS1 $(p=0.000)$, LSS3/ LSS1 $(p=0.000)$ and LSS4/LSS1 $(p=0.000)$. In Tukey's post hoc test for multiple comparisons, it was observed that the statistically significant difference was between the Control and Auriculotherapy Groups between LSS2/ LSS1 $(p=0.000)$, LSS3/LSS1 $(p=0.000)$ and LSS4/LSS1 $(p=0.000)$. The Placebo group also presented significant differences between LSS2/LSS1 $(p=0.048)$, LSS3/LSS1 $(p=0.006)$, and LSS4/LSS1 $(p=0.023)$. In percentage terms, there was an improvement of $39.90 \%$ in the LSS $2 / 1,45.39 \%$ in the LSS3/ 1 and $42.21 \%$ in the LSS $4 / 1$ 
for the Auriculotherapy group. In the Placebo group the percentages obtained were: $27.81 \%$ in the LSS2/1, $34.18 \%$ in the LSS3/1 and $31.72 \%$ in the LSS4/1. There were no differences between the Auriculotherapy and Placebo groups, as shown in Figure 3 below.

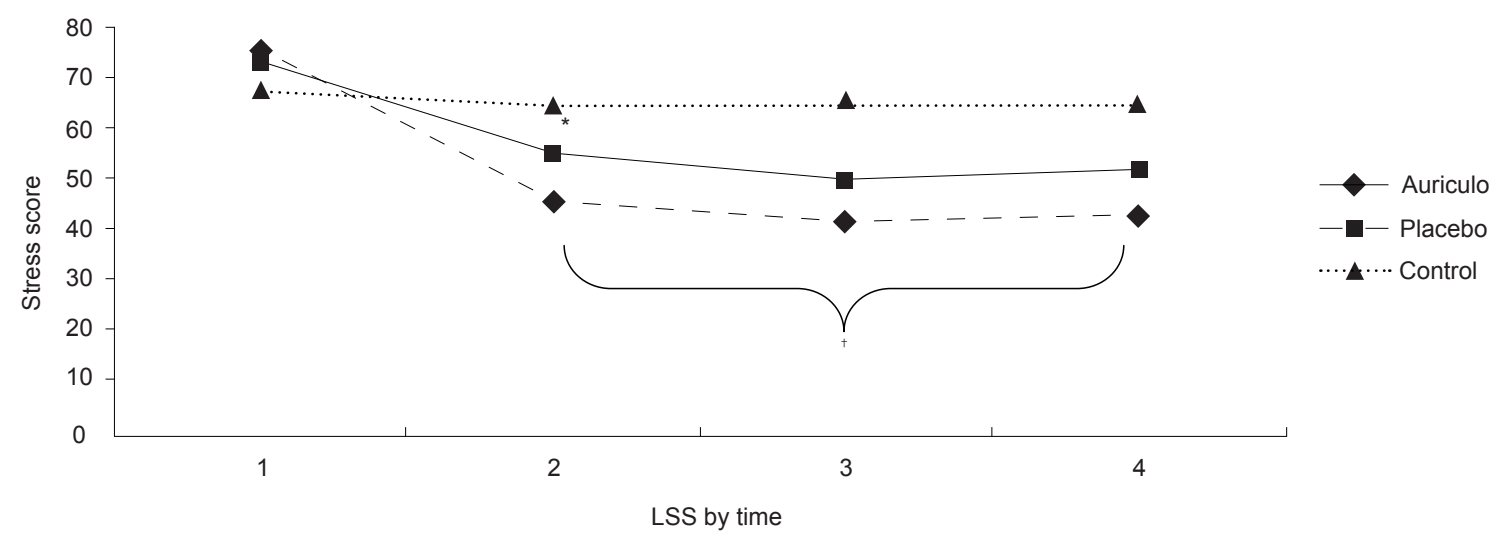
* Statistically significant difference $(p<0.05)$ for the differences between LSS2-1, LSS3-1 and LSS4-1 between the control and placebo groups.
+ Statistically significant difference $(p<0.01)$ for the differences between LSS2-1, LSS3-1 and LSS4-1 between the control and auriculotherapy
groups.

Figure 3 - Evolution of the groups according to levels of stress over time. São Paulo, SP, Brazil, 2011

The only adverse effect reported during the course of the study was the abandonment of one of the subject due to hypersensitivity and pain in the auricular.

\section{Discussion}

The points chosen for this study were once more found to be effective in reducing levels of stress. Chosen from the Chinese auriculotherapy map, the Shen Men and Brainstem points were also used with undergraduate students of Physiotherapy and Occupational Therapy, of the Faculty of Medicine of the University of São Paulo. Yellow mustard seeds were applied in 14 randomly selected subjects with high and very high levels of stress in seven sessions, held twice a week. Another 18 students comprised the Control group without intervention. When comparing the two groups, it was observed that there was a statistically significant reduction in the stress levels $(p=0.008)^{(9)}$.

Reiterating these positive findings, in another study, 75 nursing professionals from a hospital-school in São Paulo were treated using the same points, together with the Rim (energy point). Considering the seeds and semi-permanent needles, the group with needles, when compared to the control group without intervention, achieved statistically significant differences after the third evaluation, at the end of the eighth session $(p=0.023)$ and at the follow-up of 15 days $(p=0.003) *$.

These results were not, however, achieved in a clinical trial that led to the present study. The trial was the result of a Scientific Initiation Project performed in 2010, for the University of São Paulo School of Nursing, with 53 mid-level students of a technical school of massage and acupuncture. The findings did not confirm the effectiveness of such points for stress and, surprisingly, the placebo group showed slightly more positive results. It was asked, from this, what were the reasons or factors involved that could have been determinants to obtain such results? Whether they were methodological problems or an inappropriate choice of points**.

By establishing as exclusion criterion the concomitant use of other energy therapies, the present clinical trial confirmed the efficacy of auriculotherapy with semi-permanent needles to reduce stress levels, as evidenced by the statistically significant differences already at the first evaluation, after eight sessions, with better results for the Auriculotherapy Group than for the Placebo. Considering the best result, the Auriculotherapy Group, in the second evaluation after 12 sessions, achieved an improvement of $45.39 \%$ against $34.18 \%$ for the Placebo Group during the same period.

\footnotetext{
* Study entitled "Analysis of the application of different forms of auriculotherapy for stress levels in nursing professionals" presented in Chicago (September/2010), in "The $7^{\text {th }}$ Biennial Joanna Briggs Institute International Coloquium". Authors: Leonice Fumiko Sato Kurebayashi, Juliana Rizzo Gnatta, Talita Pavarini, Geysa Belisse, Suzana coca, Akemi Minami, Telma Moreira Souza, Maria Júlia Paes da Silva.

** Scientific Initiation Project of the USP School of Nursing (2010), conducted by undergraduate student Geysiane Ferreira Rocha, supervised by Prof. Maria Julia Paes da Silva and co-supervised by Leonice Fumiko Sato Kurebayashi. Presented at the SIICUSP, Ribeirão Preto (SP).
} 
The placebo effect reaches a positive result of up to $30 \%$ and therefore should be re-evaluated with greater care as the control group. It is necessary to distinguish the true placebo effect from the other nonspecific effects. Effects such as the natural course of the disease, the regression of the data around a mean, seasonal changes and unidentified interventions, such as alterations in lifestyle, need to be observed. Such factors could be controlled by a control group without treatment, so that the true placebo effect was found(17-18)

Results observed in a randomized clinical trial on the efficacy of the placebo treatment suggest that both the true acupuncture and the acupuncture with sham points produce effects and evoke physiological responses. The findings suggest that, in healthy subjects, sham acupuncture results in the activation of limbic structures, whereas deactivation is the most noticeable pattern in patients with pain; therefore, what happens to healthy subjects is not necessarily reflected in the clinical conditions of treatment. Furthermore, depending on the etiology of the pain, the response of sham acupuncture can vary positively, especially in situations concerning the emotions, producing considerably stronger effects. Given the complexity of the subject, it is recommended that the effects evaluated of the sham acupuncture be compared with a standard treatment, also taking into account the possible individual responses(19).

Regarding the sham points chosen in the present study, some factors may justify the efficacy obtained in reducing the stress of the participants. Although the Wrist point has not been indicated for the treatment of anxiety or stress, when a survey of the points close to it was performed, a point was found on a map different from the Chinese, the location of which is similar to the point for insomnia, justifying the anxiolytic action and, therefore, indicative for the decrease in the levels of stress $^{(20)}$

According to Traditional Chinese Medicine, the meridians and channels are the places where the $\mathrm{Q}$ and the vital energy of the body circulate, and they act, among other things, in the interconnection between the internal and external, the above and below, the organs and viscera. The meridians can also have a reflex area on the pinna and the wrist is the place where there two important calming and tranquilizing points are found: the Heart point 7 (H7) and the Pericardium 7 (PC7). The point 7 of the Heart meridian (Shen Men or Spirit Gate), in systemic acupuncture, is the source point and the point of sedation of the heart meridian and is located right on the wrist flexion crease, lateral to the tendon of the flexor carpi ulnaris(21).

Regarding the Outer ear point, it is initially indicated for auricular problems, labyrinthitis and seems, therefore, not to be indicated for stress. However, a point near the outer ear can be found on the French map, the effect of which is immuno-modulatory and has anti-inflammatory activity, called the interferon point ${ }^{(20)}$. It can be affirmed that there is some difficulty in establishing placebo auriculotherapy points, and this is due in part to the heterogeneity of the maps and the lack of consensus of location and indication of points. It also becomes difficult to find non-reactive points on the ear, when so many innervations in the pinna can be observed. The mechanisms of action of acupuncture are still not know and its effects can be unexpected.

In relation to the control aspect of involved factors in studies of energy practices, it is important to control whether the subjects are undergoing concomitant energy therapies or not. In a previous study conducted in the school of massage and acupuncture, the students received other therapies such as massage, moxibustion, cupping, acupuncture, as these were theoretical and practical lessons in their course. The control of these factors is recommended, because the results can be affected by this bias*.

Concerning the possible generalization of the findings of this trial, the Shen Men and Brainstem points used with semi-permanent needles resulted in positive effects in reducing symptoms of stress in nursing students, which suggests that such points may be applicable to other students. Conversely, for the sham points used in this trial, more studies are needed to affirm that they can be considered non-reactive points for stress in auriculotherapy.

The limitations of this study were: the choice of sham points and the number of subjects who participated in the study. When the placebo is an invasive intervention, a larger sample must be found so that a result can be obtained similar to a placebo with pills ${ }^{(17)}$.

\section{Conclusions}

Regarding the study participants, they were distributed predominantly within the high (64.79\%) and medium (32.39\%) stress scores and the auriculotherapy treatment with semi-permanent needles managed

* Scientific Initiation Project of the USP School of Nursing (2010), conducted by undergraduate student Geysiane Ferreira Rocha, supervised by Prof. Maria Julia Paes da Silva and co-supervised by Leonice Fumiko Sato Kurebayashi. Presented at the SIICUSP, Ribeirão Preto (SP). 
to reduce the stress levels, with better results for the Auriculotherapy group than for the Placebo group. The positive effect achieved within the first 8 sessions was maintained for 12 sessions and for 15 days after the study. In the Auriculotherapy Group the improvement reached $45.39 \%$ against $34.18 \%$ for the Placebo Group in the second evaluation. It was concluded that the Shen Men and Brainstem points were effective for stress reduction and, due to the positive results of the Placebo Group, it is suggested that further studies with a larger sample are performed so that it is possible to infer whether the Sham points used in this study, the Wrist and the Outer ear, are indeed effective in reducing stress and, therefore, are not Sham points, or if the improvement obtained of $34 \%$ was due to a true placebo response.

\section{References}

1. Evangelista RA, Hortense $P$, Sousa FAEF. Estimação de magnitude do estresse, pelos alunos de graduação, quanto ao cuidado de enfermagem. Rev. Latino-Am. Enfermagem. [periódico na Internet]. 2004. [acesso 15 dez 2011];12(6):913-7. Disponível em: http://www. scielo.br/pdf/rlae/v12n6/v12n6a10.pdf

2. Nascimento MC, Andrade A, Silva OMP, Nascimento JFM. Estresse laboral e gênero enquanto fatores associados ao risco de doenças cardiovasculares. Salusvita (Bauru) 2008;08;27(3):383-97.

3. Camelo SHH, Angerami ELS. O estresse e o profissional de enfermagem que atua na assistência à comunidade; uma revisão de literatura. Rev Nursing. [periódico na Internet]. 2006. [acesso $15 \mathrm{dez} 2011$ ];97(8):855-9. Disponível em: http://www.fen.ufg.br/revista/v10/n4/ v10n4a04.htm

4. Monteiro CLS, Freitas JFM, Ribeiro AAP. Estresse no cotidiano acadêmico: o olhar dos alunos de Enfermagem da Universidade Federal do Piauí. Esc Anna Nery. [periódico na Internet]. 2007. [acesso $15 \mathrm{dez}$ 2011];11(1): 66-72. Disponível em: http://www.scielo. br/pdf/ean/v11n1/v11n1a09.pdf

5. Nogueira-Martins MCF. Humanização na Saúde. Rev Ser Médico. 2002;18:27-9.

6. Borges AMB, Carlotto MS. Síndrome de Burnout e Fatores de Estresse em Estudantes de um Curso Técnico de Enfermagem. Aletheia. 2004;(19):45-56.

7. Secretaria Municipal de Saúde (São Paulo) (BR). Caderno Temático em Medicina Tradicional Chinesa. [Internet]. São Paulo; 2002. [acesso 22 ago 2011]. Disponível em:
8. Arai YCP, Ito A, Hibino S, Ueda W. Auricular acupunctures are effective for the prevention of postoperative agitation in old patients. Evid Based Complement Alternat. Med(eCAM). 2010;7(3):383-6.

9. Nakai LS, Lyra C, Marque AP. Eficácia da auriculoterapia na diminuição dos níveis de estresse e ansiedade de adultos saudáveis. São Paulo; 2007. [acesso $10 \mathrm{dez}$ 2011]. Disponível em: https://sistemas.usp.br/siicusp/ cdOnlineTrabalhoVisualizarResumo?numeroInscricaoTra balho $=1763$ \& numeroEdicao $=16$

10. Kober A, Scheck T, Shubert B, Strasser H, Gustorff B, Bertalanffy $P$ et al. Auricular acupressure as a treatment for anxiety in prehospital transport settings. Am Soc Anesthesiol [periódico na Internet]. 2003 [acesso $13 \mathrm{dez}$ 2011];98(6):1328-32. Disponível em: http://journals. Iww.com/anesthesiology/Abstract/2003/06000/ Auricular_Acupressure_as_a_Treatment_for_ Anxiety.5.aspx

11. Wang SM, Kain, ZN. Auricular acupuncture: a potential treatment for anxiety. Anesth Analg [periódico na Internet]. 2001 [acesso $13 \mathrm{dez} 2011$ ];92:548-53. Disponível em: http://www.anesthesia-analgesia.org/ content/92/2/548.long

12. Gori L, Firenzuoli F. Ear Acupuncture in European Traditional Medicine. Evid Based Complement Alternat Med [periódico na Internet]. 2007 [acesso $13 \mathrm{dez}$ 2011];4(Suppl1):13-6. Disponível em: http://www. ncbi.nlm.nih.gov/pmc/articles/PMC2206232/pdf/ nem106.pdf

13. Ernst E. Auricular Acupuncture. CMAJ. 2007;176(9): 1307.

14. Conselho Federal de Enfermagem (COFEN) (BR). Resolução COFEN 328/2008. Regulamenta no Sistema COFEN/Conselhos Regionais a atividade de acupuntura e dispõe sobre o registro da especialidade [Internet]. 2008. [acesso13 dez 2011]. Disponível em: http://site. portalcofen.gov.br/node/5414

15. Ferreira EAG, Vasconcellos EG, Marques AP. Assessment of pain and stress in fibromyalgia patients. Rev Bras Reumatol. 2002;42:104-10.

16. Giaponesi ANL, Leão ER. A auriculoterapia como intervenção para redução do estresse da equipe de enfermagem em terapia intensiva. Nursing (São Paulo). 2009;12(139):575-9.

17. Birch S. Controlling for non-specific effects of acupuncture in clinical trials. Clin Acupuncture Oriental Med. 2003;4:59-70.

18. Linde K, Niemann K, Schneider A, Meissner K. How large are the nonspecific effects os acupuncture? A meta-analysis of randomized controlled trials. BMC 
Medicine. [periódico na Internet]. 2010 [acesso $13 \mathrm{dez}$ 2011];8:75. Disponível em: http://www.biomedcentral. com/1741-7015/8/75

19. Lundeberg T, Lund I, Sing A, Näslund J. Is placebo acupuncture what it is intended to be? Evid Based Complement Alternat Med (eCAM). [periódico na Internet]. 2009 [acesso $13 \mathrm{dez}$ 2011]:1-5. Disponível em: http://www.ncbi.nlm.nih.gov/pmc/articles/ PMC3139519/pdf/ECAM2011-932407.pdf

20. Landgren K. Ear Acupuncture: a practical guide. Philadelphia: Churchill Livinsgtone; 2008.

21. World Health Organization (WHO). Who Standard Acupuncture Point Locations in the Western Pacific Region. [Internet]. Geneva; 2008. [acesso $13 \mathrm{dez} 2011$ ]. Disponível em: http://www.scribd.com/doc/30108330/ WHO-Standard-Accupuncture-Point-Locations 